\title{
Appropriateness of colonoscopy in Europe (EPAGE II) Functional bowel disorders: pain, constipation and bloating
}

Authors

Institutions
S. Schusselé Filliettaz ${ }^{1}$, J.-J. Gonvers ${ }^{2}$, I. Peytremann-Bridevaux ${ }^{1}$, C. Arditi' ${ }^{1}$, M. Delvaux $^{3}$, M. E. Numans ${ }^{4}$, V. Lorenzo-Zúñiga ${ }^{5}$, R. W.Dubois ${ }^{6}$, P. Juillerat ${ }^{2}$, B. Burnand ${ }^{1}$, V. Pittet ${ }^{1}$, J.-P. Vader ${ }^{1}$, F. Froehlich ${ }^{2,7}$ and the EPAGE II Study Group ${ }^{8}$

Institutions are listed at the end of article. submitted 17 June 2008 accepted after revision 5 December 2008

Bibliography

Dol $10.1055 / \mathrm{s}-0028-1119625$

Endoscopy 2009; 41:

234-239 @ Georg Thieme Verlag KG Stuttgart · New York ISSN 0013-726X

Corresponding author F. Froehlich, MD

Rue Achille-Merguin 44 $\mathrm{CH}-2900$ Porrentruy Switzerland

Fax: +4132466 2955

florian.froehlich@bluewin.ch
Background and study aims: To summarize the published literature on assessment of appropriateness of colonoscopy for the investigation of functional bowel symptoms, and report appropriateness criteria developed by an expert panel, the 2008 European Panel on the Appropriateness of Gastrointestinal Endoscopy, EPAGE II.

Methods: A systematic search of guidelines, systematic reviews and primary studies regarding the evaluation and management of functional bowel symptoms was performed. The RAND/ UCLA Appropriateness Method was applied to develop appropriateness criteria for colonoscopy for these conditions.

Results: Much of the evidence for use of colonoscopy in evaluation of chronic abdominal pain, and/or constipation and/or abdominal bloating is modest. Major limitations include small numbers of patients and lack of adequate characterization of these patients. Large community-based follow-up studies are needed to enable better definition of the natural history of patients with func-

\section{Introduction}

$\nabla$

Several definitions have been used to describe chronic constipation, using features such as type and consistency of stools, frequency of bowel movements and duration of symptoms (chronic/ acute) [1 -4]. Nonacute/chronic lower abdominal pain relies on patients' subjective sensations (onset, duration) [5]. Bloating refers both to a subjective sensation and to the objective abdominal distension. We used 3 months' duration as a cutoff point for these three nonspecific abdominal symptoms.

The definition of irritable bowel syndrome (IBS) is complex and has been subject to considerable modification over the years. (For the Rome III criteria see Table e1; for a comparison of the Rome II and III criteria see Table e2). Table A gives definitions related to lower abdominal func- tional bowel disorders. Guidelines stress that alarm features ("red flags"), such as rectal bleeding, anemia, weight loss, nocturnal symptoms, family history of colon cancer, age of onset $>50$ years, and recent onset of symptoms should all lead to careful evaluation before a diagnosis of functional bowel disorder is made. EPAGE II assessed these symptoms by means of 12 clinical scenarios, rating colonoscopy as appropriate, uncertain and inappropriate in $42 \%$ (5/12), $25 \%$ (3/12), and $33 \%(4 / 12)$ of these, respectively.

Conclusions: Evidence to support the use of colonoscopy in the evaluation of patients with functional bowel disorders and no alarm features is lacking. These patients have no increased risk of colon cancer and thus advice on screening for this is not different from that for the general population. EPAGE II criteria, available online (http:// www.epage.ch), consider colonoscopy appropriate in patients of $>50$ years with chronic or newonset bowel disturbances, but not in patients with isolated chronic abdominal pain.

tional bowel disorders as used by EPAGE II. IBS is a disorder characterized by abdominal pain or discomfort associated with defecation and/or a change in bowel habits (diarrhea and/or constipation), and by features of disordered defecation [2], with characteristic symptoms being present during the previous 3 months and with onset $>6$ months previously [2].

The prevalence of constipation in the general population[6-8] ranges from $2 \%$ to $30 \%$. Women seem to be more frequently affected than men (female-to-male ratio $2: 1$ ). Bloating is experienced at least once a month in $16 \%$ of healthy individuals [9]. In the general population, about $10 \%-$ $30 \%$ of adults have symptoms consistent with IBS, and most studies show a preponderance of females[10-13]. There are many reasons why a patient might experience symptoms such as 


\begin{tabular}{|c|c|}
\hline Term & Definition \\
\hline Uncomplicated & $\begin{array}{l}\text { None of following: melena, hematochezia, hemoccult-positive stools, unexplained } \\
\text { iron-deficiency anemia, weight loss. }\end{array}$ \\
\hline Lower abdominal pain & Pain or discomfort below the umbilicus, with or without bloating. \\
\hline $\begin{array}{l}\text { Empirical inflammatory } \\
\text { bowel syndrome (IBS) } \\
\text { therapy }\end{array}$ & $\begin{array}{l}\text { At least } 2 \text { weeks of daily treatment with fiber (psyllium- or methylcellulose-containing } \\
\text { preparations) or antispasmodics (dicyclomine, propantheline, hyscosamine, lopera- } \\
\text { mide, diphenoxylate). Empirical therapy does not allow prediction of endoscopic le- } \\
\text { sions; therefore, it does not appear in the matrix though widely used in clinical prac- } \\
\text { tice. }\end{array}$ \\
\hline $\begin{array}{l}\text { Risk factors for colorectal } \\
\text { cancer }\end{array}$ & $\begin{array}{l}\text { Personal history of colorectal cancer (CRC) or colorectal adenomas, inflammatory } \\
\text { bowel disease (IBD) } \\
\text { Or: } \\
\text { Family history of a first-degree relative with CRC or colorectal adenomas, familial } \\
\text { polyposis syndrome, hereditary nonpolyposis colorectal cancer (HNPCC) syndrome }\end{array}$ \\
\hline Lower Gl investigations & $\begin{array}{l}\text { Sigmoidoscopy or barium enema since onset of lower abdominal pain or within past } \\
5 \text { years }\end{array}$ \\
\hline Barium enema & Double-contrast technique. \\
\hline Sigmoidoscopy & Flexible tube $(60 \mathrm{~cm})$ \\
\hline Constipation therapy & $\begin{array}{l}\text { At least } 2 \text { weeks of daily treatment with fibers (psyllium- or methycellulose-containing } \\
\text { preparations) }\end{array}$ \\
\hline Constipation & $\begin{array}{l}\text { Two or more of the following symptoms for at least } 3 \text { months: } 2 \text { or fewer bowel } \\
\text { movements per week, hard stools more than } 25 \% \text { of the time, straining more than } 25 \% \\
\text { of the time, or incomplete evacuation more than } 25 \% \text { of the time }\end{array}$ \\
\hline $\begin{array}{l}\text { Chronic bowel } \\
\text { disturbances }\end{array}$ & $\begin{array}{l}\text { Change in bowel habits (mainly constipation) with/without bloating of at least } 3 \\
\text { months' duration. }\end{array}$ \\
\hline $\begin{array}{l}\text { New-onset bowel } \\
\text { disturbances }\end{array}$ & $\begin{array}{l}\text { Change in bowel habits of }<3 \text { months duration (excluding isolated diarrhea which is } \\
\text { dealt with in the companion article about diarrhea) }\end{array}$ \\
\hline
\end{tabular}

Table A Definitions related to lower abdominal functional bowel disorders. chronic constipation and/or lower abdominal pain and/or bloating [14-17].

Thus the main difficulty is to differentiate between organic and functional disorders. Although diagnostic colonoscopy may be useful for such patients, its appropriateness is questioned $[18,19]$.

In April 2008, a multidisciplinary European expert panel convened in Montreux, Switzerland, to discuss and develop criteria for the appropriate use of colonoscopy. The RAND Appropriateness Method was chosen for this purpose, because it allows the development of appropriateness criteria based on published evidence and supplemented by explicit expert opinion. A detailed description of the application of the RAND Appropriateness Method, including the literature search process, is published separately in a companion article in this issue [20].

This article presents the literature review on the appropriateness of colonoscopy in functional bowel disorders (chronic constipation and/or pain and/or bloating) that was provided to the panelists before the panel meeting, to support their ratings of appropriateness of use of colonoscopy in such circumstances; their ratings are also reported here. This updates a previous literature review published in 1999 [21].

The present chapter refers to diagnostic colonoscopy only. Patients considered here for colonoscopic evaluation would have no risk factor for colorectal cancer (CRC), except for age, and none of the following so-called alarm or "red flag" symptoms: hematochezia; positive fecal occult blood test (FOBT); anemia; personal/family history of colon cancer; personal/family history of inflammatory bowel disease; weight loss of $\geq 5 \mathrm{~kg}$; severe, persistent constipation that is unresponsive to treatment; recentonset constipation in an elderly patient without any evidence of a possible primary cause; abdominal pain/discomfort associated with exercise, movement, urination, or menstruation; fever; presence of an abdominal mass; or HIV/AIDS [22 - 25]. A companion article deals with chronic diarrhea including occasional isolated patients with functional diarrhea. The following disorders are also not considered in this article: diverticular disease, diverticulitis, metabolic conditions, and drug artifacts.

\section{Methods}

The literature review process included a systematic search of websites issuing guidelines and of Medline (1997-February 2008) to select published guidelines, systematic reviews, and primary studies assessing the use of colonoscopy in patients with functional bowel disorders. With the exception of certain relevant articles, the literature published before 1997 is presented in the previous literature review [21].

As mentioned above, the application of the RAND/UCLA Appropriateness Method is described in detail in a companion article in this issue[20]. Briefly, this process is a formal explicit expert panel method that allows classification of each indication into one of the following categories of appropriateness: inappropriate; uncertain; appropriate; appropriate and necessary (that is, the indication mandates the procedure).

To simplify the graphical presentation of the appropriateness results, these four categories were consolidated into two clusters: "Appropriate" (including "appropriate," and "appropriate and necessary") and "Not appropriate" (comprising "inappropriate" and "uncertain"). In addition to simplification and enhanced clarity of presentation, the rationale for this choice was that in many instances in the case of a nonappropriate scenario, whether it be uncertain or inappropriate, the decision for not proposing the colonoscopy should be specifically discussed and shared with the patient. All clinical indications and their ratings are available on the EPAGE website (www.epage.ch). 


\section{Results}

$\nabla$

\section{Literature review}

Eight primary studies investigating the diagnostic yield of colonoscopy in patients presenting chronic constipation and/or abdominal pain and/or bloating and published between 1997 and February 2008 were identified; 21 guidelines published over the same period on the use of colonoscopy in such patients were retrieved.

Primary studies [26-33] (see also [34]) investigating the diagnostic yield of colonoscopy in patients presenting such symptoms show very variable rates, with a variety of findings in $10 \%$ to $70 \%$ of the cases (Table e3). Guidelines [17,22 - 25, 35 - 50] (Table e4) show no clear consensus on the role of colonoscopy in the diagnosis of patients presenting chronic constipation and/or lower abdominal pain and/or bloating. Patient groups presenting such nonspecific symptoms tend to be classified according to age and whether or not they have associated alarm symptoms and/or "red flags" for organic disease. Lower gastrointestinal endoscopic evaluation would then be justified for patients $\geq 50$ years with recent-onset complaints or for any patients with complaints associated with alarm features. There is no clear consensus on whether the initial procedure in patients presenting these nonspecific symptoms should be a sigmoidoscopy or a colonoscopy.

In patients presenting with chronic constipation and/or lower abdominal pain and/or bloating, practitioners might principally consider performing a colonoscopy to exclude colorectal cancer (CRC). In primary studies [51-61], chronic constipation thus does not unequivocally appear to constitute an indicator or a risk factor for colonic neoplasia (Table e5). The literature does not give a clear indication as to whether individuals presenting with chronic constipation and/or abdominal pain and/or bloating should be considered "asymptomatic" thus being eligible for "colorectal cancer screening," or "symptomatic" thus justifying the search for a potential colonic pathology [26]. Some CRC screening/surveillance guidelines $[35,36,47]$ do mention chronic constipation and/or lower abdominal pain and/or bloating as possible symptoms likely to raise concern about the presence of CRC, while most of them do not [62-71]. The prevalence of organic disease such as CRC or inflammatory bowel disease (IBD) is not elevated in patients with IBS, compared with that in a control population [38]. Only the French guidelines from ANAES [35] recommend that a total colonoscopy be performed to identify a potential colonic neoplasia in patients with nonspecific abdominal symptoms of recent onset and which are unresponsive to treatment, if symptoms appear $>50$ years of age, or if symptoms appear $<50$ years of age and if symptomatic treatment does not have positive results.

\section{EPAGE II appropriateness criteria}

The panelists assessed lower abdominal symptoms (chronic constipation/abdominal pain/bloating) in three categories: chronic abdominal pain only, chronic bowel disturbances, and new-onset bowel disturbances (see $\bullet$ Table A for definitions used by the panel). Patients with known inflammatory bowel disease, anemia, or positive FOBT were explicitly excluded from this set of scenarios.

Out of 463 indication scenarios presented to the panel, 12 pertained to these symptoms; in 5/12 scenarios colonoscopy was

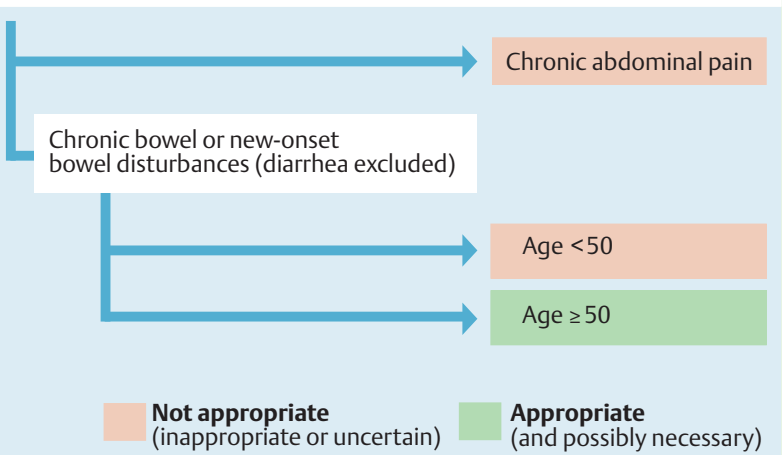

Fig. 1 a Appropriateness ratings of clinical indications for performing colonoscopy in patients with lower abdominal symptoms (simplified decision tree).

considered appropriate, in 3/12 uncertain, and in 4/12 it was considered inappropriate. $\bullet$ Fig. $\mathbf{1}$ a is a color-coded presentation of the results in a clustered dichotomy of "Not appropriate" (inappropriate or uncertain), versus "Appropriate" (appropriate or both appropriate and necessary). Isolated chronic abdominal pain was considered not appropriate for colonoscopy, as well as chronic or new-onset bowel disturbances in patients younger than 50 years. Chronic or new-onset bowel disturbances in those over 50 years of age were appropriate and potentially necessary (i.e. mandating) indications.

Fig. e1b presents appropriateness criteria in more detail. With isolated chronic abdominal pain, colonoscopy is considered inappropriate in individuals younger than 50 years, and of uncertain appropriateness in individuals 50 years or older. Patients with chronic bowel disturbances (i.e. mainly constipation under 50 years) are not considered appropriate candidates for colonoscopy under 50 years. In contrast to isolated abdominal pain, change in bowel habits of at least 3 months' duration is deemed appropriate for colonoscopy in patients aged 50 years or more. In patients under 50 years with new-onset bowel disturbances (new onset constipation with/without bloating, excluding diarrhea), panelists strongly disagreed, resulting in an "uncertain" rating. In contrast, patients with similar complaints but aged 50 years or more are all considered appropriate candidates for colonoscopy. If the procedure had never been performed previously, or was done 5 years or more previously, then colonoscopy was even deemed necessary (mandatory) in this clinical situation.

The panelists did not consider response to irritable bowel syndrome therapy as an important factor when taking decisions about appropriateness of colonoscopy.

All the clinical indications and their ratings are available online (http://www.epage,ch), where answering a few clinical questions allows the appropriateness score for each indication to be obtained.

\section{Conclusions}

$\nabla$

Primary studies evaluating the appropriateness of colonoscopy in patients presenting nonspecific symptoms such as chronic constipation and/or lower abdominal pain and/or bloating are of modest quality. Most of them are retrospective case series without control groups. The variations among results can be explained by the heterogeneity in measured outcomes, study design, samples, definitions, indications for colonoscopy and/or in- 
clusion criteria, which may also reflect the discrepancies in and the evolution of the definitions, and the still unknown etiologies of these nonspecific symptoms. Direct comparisons of results between studies, as well as generalization and recommendations for all individuals with chronic constipation and/or abdominal pain and/or bloating are therefore difficult. Guidelines on these topics must therefore be interpreted with caution since they are mainly based on modest evidence and on expert opinion. The complaints dealt with in this article are difficult to define clinically and often overlap, but are extremely frequent: chronic constipation and/or lower abdominal pain and/or bloating are mainly indicators of functional disease. This review of the published literature highlights the fact that, despite the modest quality of the evidence, and although the presence of these symptoms probably does not enhance the pick-up rate of CRC per se, recommendations tend to consider screening purposes associated with clinical symptoms as a reason for performing colonoscopy. The notion of alarm symptoms ("red flags") is used to differentiate between symptoms of functional disease in which colonoscopy probably is of little help, and symptoms of organic disease in which colonoscopy would be appropriate. Colonoscopic evaluation may thus be justified for patients aged $\geq 50$ years with recentonset complaints (chronic constipation and/or abdominal pain and/or bloating) or for any patients with such complaints in association with alarm symptoms.

The EPAGE II panel considered chronic as well as new-onset changes in bowel habits in patients aged $\geq 50$ years to be appropriate indications for performing colonoscopy. In contrast, isolated pain is not deemed to be an appropriate indication whatever the patients' age. New-onset bowel disturbances at $\geq 50$ years are necessary (i.e. mandating) indications for colonoscopy. The EPAGE II panel results show the importance of the cutoff age of 50 years for the decision as to whether colonoscopy should be performed in patients with lower abdominal symptoms such as abdominal pain, constipation, and bloating.

\section{Acknowledgments \\ $\nabla$}

The authors gratefully acknowledge the selfless commitment and invaluable contribution of the expert panel members, who made this project possible: Lars Agréus (SE), Christoph Beglinger $(\mathrm{CH})$, Peter Bytzer (DK), Michel Delvaux (FR), Volker F. Eckardt (DE), Peter D. Fairclough (UK), François Lacaine (FR), Olivier Le Moine (BE), Vicente Lorenzo Zúñiga Garcia (ES), Giorgio Minoli (IT), Mattijs E. Numans (NL), Daniel Oertli (CH), John O"Malley (UK), Alastair Windsor (UK). The authors warmly thank Susan Giddons for her invaluable assistance in the administration of the expert panel process, as well as in the meticulous preparation of the manuscripts.

\section{Appendix: The EPAGE II Study Group \\ $\nabla$}

See page 205.

\section{Competing interests: None}

\footnotetext{
* See Appendix: The EPAGE II Study Group
}

\section{Institutions}

1 Healthcare Evaluation Unit, Institute of Social and Preventive Medicine (IUMSP), Centre Hospitalier Universitaire Vaudois and University of Lausanne, Lausanne, Switzerland

2 Department of Gastroenterology and Hepatology, Centre Hospitalier Universitaire Vaudois and University of Lausanne, Lausanne, Switzerland

3 Department of Internal Medicine and Digestive Pathology, CHU de Nancy, Vandoeuvre-les-Nancy, France

4 Julius Center for Health Sciences and Primary Care, University Medical Center Utrecht, Utrecht, The Netherlands

5 Gastroenterology/Endoscopy, Hospital Universitari Germans Trias I Pujol, Badalona (Barcelona), Spain

${ }^{6}$ Cerner LifeSciences, Beverly Hills, USA

7 Department of Gastroenterology, University of Basle, Basle, Switzerland

8 The EPAGE II Study Group*

\section{References}

1 Drossman DA. The functional gastrointestinal disorders and the Rome II process. Gut 1999; 45 Suppl 2: II1 - II5

2 Drossman DA. The functional gastrointestinal disorders and the Rome III process. Gastroenterology 2006; 130: 1377-1390

3 Lewis SJ, Heaton KW. Stool form scale as a useful guide to intestinal transit time. Scand J Gastroenterol 1997; 32: 920-924

4 Manning AP, Thompson WG, Heaton KW, Morris AF. Towards positive diagnosis of the irritable bowel. Br Med J 1978; 2: 653-654

5 Tougas $G$. The nature of pain in irritable bowel syndrome. J Clin Gastroenterol 2002; 35: S26-S30

6 Garrigues V, Galvez C, Ortiz V et al. Prevalence of constipation: agreement among several criteria and evaluation of the diagnostic accuracy of qualifying symptoms and self-reported definition in a populationbased survey in Spain. Am J Epidemiol 2004; 159: 520-526

7 Higgins PD, Johanson JF. Epidemiology of constipation in North America: a systematic review. Am J Gastroenterol 2004; 99: 750 - 759

8 Pare P, Ferrazzi S, Thompson WG et al. An epidemiological survey of constipation in Canada: definitions, rates, demographics, and predictors of health care seeking. Am J Gastroenterol 2001; 96: 3130 - 3137

9 Sandler RS, Stewart WF, Liberman JN et al. Abdominal pain, bloating, and diarrhea in the United States: prevalence and impact. Dig Dis Sci 2000; 45: 1166-1171

10 Hungin AP, Whorwell PJ, Tack J, Mearin F. The prevalence, patterns and impact of irritable bowel syndrome: an international survey of 40000 subjects. Aliment Pharmacol Ther 2003; 17: 643-650

11 Mueller-Lissner SA, Bollani S, Brummer RJ et al. Epidemiological aspects of irritable bowel syndrome in Europe and North America. Digestion 2001; 64: 200-204

12 Saito YA, Schoenfeld P, Locke GR, III. The epidemiology of irritable bowel syndrome in North America: a systematic review. Am J Gastroenterol 2002; 97: 1910-1915

13 Thompson WG, Heaton KW, Smyth GT, Smyth C. Irritable bowel syndrome in general practice: prevalence, characteristics, and referral. Gut 2000; 46: 78-82

14 Agrawal A, Whorwell PJ. Review article: abdominal bloating and distension in functional gastrointestinal disorders - epidemiology and exploration of possible mechanisms. Aliment Pharmacol Ther 2008; 27: $2-10$

15 Kalloo AN. Overview of differential diagnoses of abdominal pain. Gastrointest Endosc 2002; 56: S255-S257

16 Leung FW. Etiologic factors of chronic constipation: review of the scientific evidence. Dig Dis Sci 2007; 52: 313-316

17 Locke GR III, Pemberton JH, Phillips SF. American Gastroenterological Association technical review on constipation. Gastroenterology 2000; 119: $1766-1778$

18 Bond JH. Is referral for colonoscopy underutilized by primary care physicians? Gastrointest Endosc 2000; 52: 693-696

19 Vader JP, Pache I, Froehlich Fet al. Overuse and underuse of colonoscopy in a European primary care setting. Gastrointest Endosc 2000; 52: 593-599

20 Juillerat P, Peytremann-Bridevaux I, Vader JP et al. Appropriateness of colonoscopy in Europe (EPAGE II). Presentation of methodology, general results, and analysis of complications. Endoscopy 2008; 41:

21 DeBosset V, Gonvers JJ, Vader JP et al. Appropriateness of colonoscopy: lower abdominal pain or constipation. Endoscopy 1999; 31: 637640 
22 Brandt LJ, Prather CM, Quigley EM et al. Systematic review on the management of chronic constipation in North America. Am J Gastroenterol 2005; 100 Suppl 1: S5 - S21

23 Longstreth GF, Thompson WG, Chey WD et al. Functional bowel disorders. Gastroenterology 2006; 130: 1480 - 1491

24 Piche T, Dapoigny M, Bouteloup C et al. Recommandations pour la pratique clinique dans la prise en charge et le traitement de la constipation chronique de l'adulte. Gastroenterol Clin Biol 2007; 31: 125 - 135

25 Sowerby Centre for Health Informatics. Constipation in adults. Newcastle, UK: SCHIN, 2005

26 Adler A, Roll S, Marowski B et al. Appropriateness of colonoscopy in the era of colorectal cancer screening: a prospective, multicenter study in a private-practice setting (Berlin Colonoscopy Project 1, BECOP 1). Dis Colon Rectum 2007; 50: 1628 - 1638

27 DeBosset V, Froehlich F, Rey JP et al. Do explicit appropriateness criteria enhance the diagnostic yield of colonoscopy? Endoscopy 2002; 34: $360-368$

28 Duncan JE, Sweeney WB, Trudel JL et al. Colonoscopy in the elderly: low risk, low yield in asymptomatic patients. Dis Colon Rectum 2006; 49: $646-651$

29 Gonvers JJ, Harris JK, Wietlisbach V et al. A European view of diagnostic yield and appropriateness of colonoscopy. Hepatogastroenterology 2007; 54: 729 - 735

30 Lasson A, Kilander A, Stotzer PO. Diagnostic yield of colonoscopy based on symptoms. Scand J Gastroenterol 2007; : 1 - 7

31 Lieberman DA, de Garmo PL, Fleischer DE et al. Colonic neoplasia in patients with nonspecific GI symptoms. Gastrointest Endosc 2000; 51: $647-651$

32 Morini S, Hassan C, Meucci G et al. Diagnostic yield of open access colonoscopy according to appropriateness. Gastrointest Endosc 2001; 54: $175-179$

33 Pepin $C$, Ladabaum $U$. The yield of lower endoscopy in patients with constipation: survey of a university hospital, a public county hospital, and a Veterans Administration medical center. Gastrointest Endosc 2002: 56: $325-332$

34 Froehlich F, Gonvers JJ. Diagnostic yield of colonoscopy by indication. In: Waye JD, Rex DK, Williams CB, eds Colonoscopy: principles and practice. Malden, Massachusetts, USA: Blackwell Publishing, 2003: $111-130$

35 Agence Nationale d'Accréditation et d'Evaluation en Santé. Endoscopie digestive basse: indications en dehors du dépistage en population Argumentaire. Saint-Denis La Plaine: Haute Autorité de Santé, 2004

36 Australian Cancer Network Colorectal Cancer Guidelines Revision Committee. Guidelines for the prevention, early detection and management of colorectal cancer. Sydney: The Cancer Council Australia and Australian Cancer Network, 2005

37 Bleser SD. Practical symptom-based evaluation of chronic constipation. J Fam Pract 2006; 55: 580 - 584

38 Brandt LJ, Bjorkman D, Fennerty $M B$ et al. Systematic review on the management of irritable bowel syndrome in North America. Am J Gastroenterol 2002; 97: S7 - S26

39 Camilleri $M$, Heading RC, Thompson WG. Clinical perspectives, mechanisms, diagnosis and management of irritable bowel syndrome. Aliment Pharmacol Ther 2002; 16: 1407-1430

40 Drossman DA, Camilleri M, Mayer EA, Whitehead WE. American Gastroenterological Association technical review on irritable bowel syndrome. Gastroenterology 2002; 123: 2108 - 2131

41 Fass R, Longstreth GF, Pimentel $M$ et al. Evidence- and consensus-based practice guidelines for the diagnosis of irritable bowel syndrome. Arch Intern Med 2001; 161: 2081 - 2088

42 Horwitz BJ, Fisher RS. The irritable bowel syndrome. N Engl J Med 2001; 344: $1846-1850$

43 Houghton LA, Whorwell PJ. Towards a better understanding of abdominal bloating and distension in functional gastrointestinal disorders. Neurogastroenterol Motil 2005; 17: 500-511

44 Jones J, Boorman J, Cann P et al. British Society of Gastroenterology guidelines for the management of the irritable bowel syndrome. Gut 2000; 47 Suppl 2: ii1 - 19

45 Qureshi W, Adler DG, Davila RE et al. ASGE guideline: guideline on the use of endoscopy in the management of constipation. Gastrointest Endosc 2005; 62: 199-201

46 Rao SS, Ozturk R, Laine L. Clinical utility of diagnostic tests for constipation in adults: a systematic review. Am J Gastroenterol 2005; 100 : $1605-1615$

47 Singapore Ministry of Health. Colorectal cancer. Singapore, 2004: 98p
48 Spiller R, Aziz Q Creed F et al. Guidelines for the management of irritable bowel syndrome. Gut 2007; 56: $1770-1798$

49 Talley NJ. Irritable bowel syndrome. Intern Med J 2006; 36: 724-728

50 World Gastroenterology Organization. Constipation. 2007

51 Chan AO, Hui WM, Leung G et al. Patients with functional constipation do not have increased prevalence of colorectal cancer precursors. Gut 2007; 56: 451 - 452

52 Dorval E, Jankowski JM, Barbieux JP et al. Polyethylene glycol and prevalence of colorectal adenomas. Gastroenterol Clin Biol 2006; 30: 1196 - 1199

53 Dukas L, Willett WC, Colditz GA et al. Prospective study of bowel movement, laxative use, and risk of colorectal cancer among women. Am J Epidemiol 2000; 151: 958 - 964

54 Ghadirian P, Maisonneuve P, Perret C et al. Epidemiology of sociodemographic characteristics, lifestyle, medical history, and colon cancer: a case-control study among French Canadians in Montreal. Cancer Detect Prev 1998; 22: 396 - 404

55 Jacobs EJ, White E. Constipation, laxative use, and colon cancer among middle-aged adults. Epidemiology 1998; 9: 385 - 391

56 Kojima M, Wakai K, Tokudome S et al. Bowel movement frequency and risk of colorectal cancer in a large cohort study of Japanese men and women. Br J Cancer 2004; 90: 1397-1401

57 LeMarchand L, Wilkens LR, Kolonel LN et al. Associations of sedentary lifestyle, obesity, smoking, alcohol use, and diabetes with the risk of colorectal cancer. Cancer Res 1997; 57: 4787-4794

58 Otani T, Iwasaki M, Inoue $M$ et al. Bowel movement, state of stool, and subsequent risk for colorectal cancer: the Japan public health centerbased prospective study. Ann Epidemiol 2006; 16: 888-894

59 Roberts MC, Millikan RC, Galanko JA et al. Constipation, laxative use, and colon cancer in a North Carolina population. Am J Gastroenterol 2003; 98: $857-864$

60 Sonnenberg A, Muller AD. Constipation and cathartics as risk factors of colorectal cancer: a meta-analysis. Pharmacology 1993; 47 Suppl 1: $224-233$

61 Watanabe T, Nakaya N, Kurashima K et al. Constipation, laxative use and risk of colorectal cancer: The Miyagi Cohort Study. Eur J Cancer 2004; 40: $2109-2115$

62 American Cancer Society. Cancer facts and figures 2007. 56p. www. cancer.org

63 Davila RE, Rajan E, Adler D et al. ASGE guideline: the role of endoscopy in the diagnosis, staging, and management of colorectal cancer. Gastrointest Endosc 2005; 61: 1 - 7

64 Davila RE, Rajan E, Baron TH et al. ASGE guideline: colorectal cancer screening and surveillance. Gastrointest Endosc 2006; 63: 546-557

65 Institute for Clinical Systems Improvement. Colorectal cancer screening. Bloomington, Minnesota, 2006: 51p

66 Levin B, Barthel JS, Burt RW et al. Practice guidelines in Oncology: Colorectal cancer screening. National Comprehensive Cancer Network, 2007

67 McLeod $R$ and the CTFPHC. Screening strategies for colorectal cancer: systematic review and recommendations. Technical review. London, Ontario: Canadian Task Force on Preventive Health Care (CTFPHC), 2001

68 National Guideline Clearinghouse. Colorectal cancer screening clinica practice guideline - NGC summary. Oakland (USA): Kaiser Permanente Care Management Institute, 2006

69 Pignone MP, Rich M, Teutsch S et al. Screening for colorectal cancer in adults. Rockville: Agency for Healthcare Research and Quality (AHRQ), 2002

70 Rex DK, Johnson DA, Lieberman DA et al. Colorectal cancer prevention 2000: screening recommendations of the American College of Gastroenterology. American College of Gastroenterology. Am J Gastroenterol 2000; 95: $868-877$

71 Winawer S, Fletcher R, Rex D et al. Colorectal cancer screening and surveillance: clinical guidelines and rationale - Update based on new evidence. Gastroenterology 2003; 124: 544-560

72 Ternent CA, Bastawrous AL, Morin NA et al. Practice parameters for the evaluation and management of constipation. Dis Colon Rectum 2007; 50: $2013-2022$

73 American College of Gastroenterology. An evidence-based approach to the management of chronic constipation in North America. Am J Gastroenterol 2005; 100 Suppl 1: S1 - S4

74 Thompson WG, Longstreth GF, Drossman DA et al. Functional bowel disorders and functional abdominal pain. Gut 1999; 45 Suppl 2: II43 - II47 
The following figure and tables are available online: www.thieme-connect.com/media/endoscopy/200903/supmat/ endo842.pdf

Fig. e1b Appropriateness ratings of clinical indications for performing colonoscopy in patients with lower abdominal symptoms (full decision tree).

Table e1 Functional bowel disorders: Rome III definitions (adapted from [2]).

Table e2 Comparison between the Rome II and Rome III definitions of functional bowel disorders.

Table e3 Studies investigating the diagnostic yield of colonoscopy in patients presenting with chronic constipation and/or abdominal pain and/or bloating (1997 - February 2008).

Table e4 Guidelines/reviews issuing recommendations on the appropriateness of colonoscopy for diagnostic purposes in chronic constipation and/or abdominal pain and/or bloating.

Table e5 Guidelines/reviews issuing recommendations on the appropriateness of colonoscopy for diagnostic purposes in chronic constipation and/or abdominal pain and/or bloating.

Table e6 Studies investigating the association between chronic constipation and colorectal cancer (1997 - February 2008). 